\title{
Electronic Medical Record Use and Associated Factors in Diredawa, Eastern Ethiopia. A mixed Method Study
}

Abebe Tolera ( $\nabla$ komiintoler@gmail.com )

Haramaya University

Lamessa Oljira

Haramaya University

Tariku Dingeta

Haramaya University

Admas Abera Abaerei

Haramaya University

Hirbo Shore

Haramaya University

\section{Research Article}

Keywords: Electronic Medical Records, EMR, Use, Ethiopia, Developing Countries

Posted Date: February 28th, 2022

DOI: https://doi.org/10.21203/rs.3.rs-1362306/v1

License: (a) (i) This work is licensed under a Creative Commons Attribution 4.0 International License.

Read Full License 


\section{Abstract}

Background: Despite rapid growth in the information technology (IT), adoption rate of electronic medical records (EMR) in health care setting is lagging behind in Ethiopia. EMRs have long been considered as essential elements in improving healthcare quality and safety, enhance service performance, reduce adverse events for patients, and support clinical decision support system. However, utilization of EMR among healthcare providers still remains low and there has been little progress toward harnessing the benefits of EMR particularly in developing countries.

Objective: This study, therefore, is aimed at exploring EMR use and its determinants among health care providers.

Methods: Quantitative cross-sectional study was conducted on 402 health professionals working at public health facilities supplemented with an exploratory qualitative study in Dire Dawa, Ethiopia. Descriptive statistics and logistic regression analysis were used to explore determinant factors of EMR use while qualitative data were thematically analyzed.

Results: Overall, about a quarter (26.6\%) of health professionals were using electronic medical record. Work experience of 6 years or less (AOR=2.23; 95\% Cl: [1.15-4.31]), discussion on EMR (AOR=14.47; 95\% Cl: [5.58-37.57]), presence of EMR manual (AOR=3.10 95\% Cl: [1.28-7.38]), and positive attitude towards EMR system (AOR=11.15; 95\% Cl: [4.90-25.36]) and service quality (AOR=8.02; 95\% Cl: [4.09-15.72]) were independent determinants of EMR use.

Conclusion: The analysis carried out indicates that EMR use by health professionals in the study area is very low. Therefore, there is a need to leverage through continuous technical support and commitment to enhance EMR use which has the potential to improve health service performance.

\section{Introduction}

The ever increasing integration of highly diversified technologies in health care fields resulted in need for organized, accessible, timely, and accurate data for informed decision making in health sector. ${ }^{1-4}$ Evidence show that health facilities with automated notes and records, order entry, test result and clinical decision support had fewer complications, lower costs and effective in the overall health care delivery system. ${ }^{5-9}$ One of these record automations being implemented in healthcare setting is an electronic medical record (EMR) which is the legal record created in hospitals and ambulatory environments that enables health facilities to capture, store, analyze and communicate patient health information in an electronic format. ${ }^{10,11}$

Despite large investments to support the adoption of EMR, the adoption rate of such systems is still low and there has been little progress toward harnessing the benefits of EMR particularly in developing countries. ${ }^{12}$ The implementation of EMR is not consistent across healthcare facilities and its use is met with an alarming rate of failure in resource poor settings. ${ }^{13-15}$ Due to limited resources and capacities, 
most of the electronic systems are still used side by side to the paper documentation that is creating burden on health service providers. ${ }^{16-18}$

In developed countries such as United State of America, more than three-quarters of health professionals $(81.7 \%)$ are using EMR while in developing countries like Ethiopia, health professionals' use of EMR is very low. ${ }^{19,20}$ Study in sub-Saharan countries showed the complexity and impact of social considerations, outweighing product and EMR system limitations. ${ }^{21}$ Similarly, the utilization and digital health investments for planning and decision making in Ethiopia has not been a priority and generally inadequately supported and poorly managed. ${ }^{1}$

The current health sector transformation plan (HSTP) of Ethiopia envisioned all of its citizens enjoying equitable and affordable access to all types of health services through the transformation agenda of the Information Revolution. ${ }^{1}$ In this regard, the use of electronic medical record represents one of the key instruments in improving healthcare delivery. 5, 6, 22 The Ethiopian Ministry of Health with support of the Tulane University Technical Assistance Project in Ethiopia (TUTAPE) and CDC started the development and implementation of a comprehensive EMR system for hospitals called SmartCare in 2009. The system was deployed in 5 hospitals in Addis Ababa and other hospitals in regional cities. In 2013, the Ministry of Health adapted the system as a national EMR for all hospitals, and planned to scale it up to further hospitals and regions. ${ }^{23,}{ }^{24}$ All urban health facilitates in Diredawa Administration were selected for the initial phase implementation and chosen as a pilot site. ${ }^{24}$

However, the current utilization since EMR implementation in Dire Dawa is unknown. ${ }^{23}$ Moreover, there is no study conducted on the utilization status of electronic medical records and the individual and organization determinants in the study area. Therefore, this study is aimed to fill the knowledge gaps related to Electronic medical records utilization and its determinants among health care providers in Dire Dawa city administration in Eastern Ethiopia.

\section{Methods And Materials}

\section{Study design and setting}

An institution-based quantitative cross-sectional study supplemented with an exploratory qualitative approach was conducted at public health facilities in Dire Dawa city administration in eastern Ethiopia from April 7 to May 7, 2019. Dire Dawa, an industrial hub and home to several market centers, is located in the eastern Ethiopia and has 14 health centers, 2 hospitals and 32 health posts with a total of 629 health professionals including health extension workers.

\section{Study participants}

Study participants for this study are all health care providers selected randomly across 2 hospitals and 7 health centers. The sample size of 446 was estimated with an assumption of $95 \%$ confidence level, $80 \%$ 
power and $10 \%$ non-response rate. But as the numbers of healthcare providers were manageable (489) all healthcare providers were included in data collection. To better understand what factors influence EMR use, we also conducted in-depth interviews with 9 key informants who have better knowledge and experience on the EMR in their organizations. All healthcare providers that were selected randomly across the health facilities and who served for at least 6 months were approached to complete the questionnaire.

\section{Data collection and quality control methods}

Pre-tested semi-structured questionnaire were used supplemented with in-depth interview guides. These tools were adapted and constructed from PRISM tools ${ }^{25}$ and from previously conducted studies. ${ }^{23,} 26,27$ Data were collected by five clinical nurses and five health officers for quantitative data whereas two data collectors experienced with Qualitative data collection carried out the in-depth interviews. Three item questions with in-depth probing were adopted and contextualized from other studies. ${ }^{28,} 29$ Upon completion of each in-depth interviews, a trained language profession produced a complete transcript and translation. Strict supervision and double data entry were made for data quality control.

\section{Measurements}

The dependent variable, EMR Use was measured if a participant uses EMR for one or more of the following functions: (1) Find patient with certain characteristics, (2) Create notes (history and physical exam), (3) Enter order (lab, radiology), (4) Review/obtain lab and radiology results, (5) Update diagnosis, (6) Review currently received medications, (7) Write prescriptions, (8) Admit a patient, Refer a patient, (9) View/schedule appointment for a patient, (10) Communication using Smart Care's communication /Report sending, (11) Produce patient summary reports/Report generating, (12) Data retrieving and analysis. Respondent's computer skill was assessed using a 10 question score (Internet browsing, Calculations, Email communication, Data base management, ability to check data accuracy, plot data by months or years, compute trends from bar charts, explain findings \& their implications, use data for identifying gaps and setting targets, use data for making various types of decisions and providing feedback). Perceived EMR system quality was assessed using a five item questions with five scale score was used to classify it as good or bad. Similarly, perceived service quality measured using a nine item questions with five scale score was used to classify it as good or bad.

\section{Data processing and analysis}

Descriptive statistics were used to describe characteristics of study participants with EMR use. Bivariate and Multivariable logistic regression was employed to identify predictors of EMR use. All statistics with pvalue $<0.05$ declared significant. All analyses were performed using STATA version 14.1. Qualitative data collected were transcribed, coded and thematically analyzed using ATLAS.ti 7.5.4. Coding was made inductively during data analysis.

\section{Ethical Approval and consent to participate}


Ethical approval was obtained from Institutional Health Research Ethics Review Committee of Haramaya University with Reference number of IHRERC/104/2019. Permission for data collection was obtained from health facilities. Study participants were informed about the purpose, benefit and risk of the study. Written informed consent was obtained from the study participants in a form provided with the questionnaire.

\section{Results}

\section{Socio-Demographic Characteristics of study participants}

Out of the 489 study participants, $402(82.2 \%)$ responded to the questionnaires. The majority (55\%) of the respondents were females. (Table 1 ) The mean age of the respondents was 31.30 years $( \pm 6.61 \mathrm{SD}$ ). More than one third of participants (37.8\%) have more than seven years of experience whereas about three quarters $(76.6 \%)$ of the respondents were degree holders. For the qualitative in-depth interviews, 7 HMIS/HIT staffs and 2 health facility heads were involved. Five of the key informants were females. All of them were married; six of them were degree holders. 
Table 1

Socio-demographic characteristics of the study participants, Dire Dawa, Ethiopia, $2019(\mathrm{n}=402)$.

\begin{tabular}{|c|c|c|c|}
\hline Variable & Category & Freq. & Percent (\%) \\
\hline \multirow[t]{2}{*}{ Sex } & Female & 219 & 54.48 \\
\hline & Male & 183 & 45.52 \\
\hline \multirow[t]{4}{*}{ Age (years) } & $20-24$ & 36 & 8.96 \\
\hline & $25-29$ & 151 & 37.56 \\
\hline & $30-34$ & 123 & 30.60 \\
\hline & 35 and above & 92 & 22.89 \\
\hline \multirow[t]{2}{*}{ Residence } & Urban & 342 & 85.07 \\
\hline & Rural & 60 & 14.93 \\
\hline \multirow[t]{3}{*}{ Marital status } & Single & 160 & 39.80 \\
\hline & Married & 231 & 57.46 \\
\hline & Others & 11 & 2.74 \\
\hline \multirow[t]{3}{*}{ Education } & Diploma & 77 & 11.16 \\
\hline & Degree & 308 & 76.62 \\
\hline & Masters and above & 17 & 4.23 \\
\hline \multirow[t]{2}{*}{ Work experience } & $\leq 7$ years & 250 & 62.19 \\
\hline & $>7$ years & 152 & 37.81 \\
\hline \multirow[t]{5}{*}{ Profession } & All Nurses & 256 & 63.68 \\
\hline & Laboratory technicians & 45 & 11.2 \\
\hline & Physicians & 38 & 9.46 \\
\hline & Health Officers & 32 & 7.96 \\
\hline & Pharmacist & 31 & 7.71 \\
\hline \multirow[t]{5}{*}{ Average monthly Income } & $601-1650$ & 10 & 2.49 \\
\hline & $1651-3200$ & 50 & 12.44 \\
\hline & $3201-5250$ & 186 & 46.27 \\
\hline & $5251-7800$ & 97 & 24.13 \\
\hline & 7801-10900 & 43 & 10.70 \\
\hline
\end{tabular}




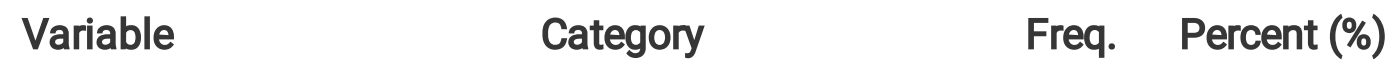 \\ Over $10900 \quad 16 \quad 3.98$ \\ Accessibility, functional status and computers skills of health professionals}

Majority of the study participants $243(60.45 \%)$ have access to at least one computer at their working desk (excluding personal computer) in which about $85 \%$ were functional at the time of the study.

(Table 2) More than two third 178 (73.25\%) of current users are using this computer(s) for data recording, and additional $141(58.02 \%)$ and $74(30.45 \%)$ of them use the available computer(s) for report generating and reading, respectively.

Table 2

Accessibility, functional status and computers skills of health-care professional, Dire Dawa $(n=402)$

\begin{tabular}{|c|c|c|c|}
\hline Variable & Categories & Frequency & $\begin{array}{l}\text { Percent } \\
(\%)\end{array}$ \\
\hline \multirow[t]{2}{*}{ Have access to computer(s) } & Yes & 243 & 60.45 \\
\hline & No & 159 & 39.55 \\
\hline \multirow[t]{4}{*}{ Number of accessible computer(s). } & One & 178 & 73.25 \\
\hline & Two & 42 & 17.28 \\
\hline & Three & 11 & 4.53 \\
\hline & $\geq$ Four & 12 & 4.94 \\
\hline \multirow[t]{2}{*}{ Computer's functionality } & Yes & 207 & 85.19 \\
\hline & No & 36 & 14.81 \\
\hline \multirow[t]{2}{*}{ Share the available computer(s) with others } & Yes & 194 & 79.84 \\
\hline & No & 49 & 20.16 \\
\hline \multirow{5}{*}{$\begin{array}{l}\text { Number of health professional(s) they share the computer } \\
\text { with }\end{array}$} & 0 & 47 & 19.34 \\
\hline & 1 & 19 & 7.82 \\
\hline & 2 & 38 & 15.64 \\
\hline & 3 & 51 & 20.99 \\
\hline & $\begin{array}{l}4 \text { and } \\
\text { above }\end{array}$ & 88 & 36.21 \\
\hline \multirow[t]{2}{*}{ Computer skill } & Fair & 202 & 50.25 \\
\hline & Poor & 200 & 49.75 \\
\hline
\end{tabular}




\section{EMR Use and related Characteristics}

Overall, $388(96.52 \%)$ of the participants have heard of electronic medical record and more than half (54.48\%) of them have used it before. Just over a quarter $107(26.61 \%)$ of health professionals are currently using EMR. The most commonly used features of EMR are for sending reports $(46.12 \%)$ followed by finding patients with certain characteristics $42.01 \%$ (Fig. 1).

Furthermore, about two thirds of current users $71(66.4 \%)$ were nurses, followed by laboratory technicians 15 (14.02\%), health officers 10 (9.35\%), physicians 10 (9.35\%) and pharmacists. Moreover, main reported reasons of not currently using EMR were unavailability of functional installed EMR software programme (the SmartCare installed by Tulane University is outdated due project phase-out (Fig. 2).

The majority $260(64.68 \%)$ of the participants have received HMIS training while $267(66.42 \%)$ have been trained on EMR. However, only $174(65.17 \%)$ of the participants used EMR after the training and only 63 (15.67\%) of the participants own EMR manual. Furthermore, only 33 (8.21\%) participants held regular discussion on EMR during performance monitoring team meeting.

\section{Health professionals' acceptance and attitude towards EMR}

In general, when respondents are asked about EMR, 287 (71.39\%), 256 (63.68\%), 255 (63.43\%), 266 $(66.17 \%)$ of them agreed that they fully accept it, believed that it improved their productivity, preferred EMR over paper based record, and agreed electronic recording of patient data have an impact on data quality, respectively. Moreover, there was significant difference in EMR use among health care providers with respect to their attitude on EMR service quality, EMR system quality and perceived EMR information quality (Fig. 3).

\section{Factors associated with EMR use}

In the final multivariable logistic regression, the following variables were found to independently predict EMR use; work experience, access to EMR manual, having discussion on EMR, positive perceived EMR system quality, perceived service quality and perceived benefit of EMR. (Table 3)

Respondents with work experience of 6 years or less were about two times more likely to use EMR system than those with work experience of greater than 6 years $(\mathrm{AOR}=2.13 ; 95 \% \mathrm{Cl}=[1.08-4.20])$. Study participants who have access to EMR manual were three times more likely to use the EMR system than those who have no EMR manual $(\mathrm{AOR}=3.01 ; 95 \% \mathrm{Cl}=[1.23-7.40])$. Those health professionals who reported to discuss on EMR issues in any meeting were about 15 times more likely to use EMR compared to those who didn't have discussion on EMR $(A O R=15.23 ; 95 \% \mathrm{Cl}=[5.70-40.74])$. Respondents with good perceived EMR service quality were eight times more likely to use EMR than those with poor perception of EMR service quality $(\mathrm{AOR}=8.31 ; 95 \% \mathrm{Cl}=[4.11-16.80])$. Similarly, respondents with good EMR system quality were about 7 times more likely to use EMR than those with poor perceived EMR system quality $(\mathrm{AOR}=7.38 ; 95 \% \mathrm{Cl}[2.97-18.34])$. 
Health professionals who think EMR will benefit the patients are about 5.5 times more likely to use EMR than those who said it will not benefit patients [AOR: $5.51 ; 95 \% \mathrm{Cl}(1.10-27.67)$ ]. (Table 3 ) 
Table 3

Factors associated with EMR use by health professionals working in urban Public health facilities Dire Dawa Ethiopia, $2019(\mathrm{n}=402)$.

\begin{tabular}{|c|c|c|c|c|c|c|}
\hline \multirow[t]{2}{*}{ Variables } & \multirow[t]{2}{*}{ Response } & \multicolumn{2}{|c|}{ EMR use (\%) } & \multirow{2}{*}{$\begin{array}{l}\text { COR } \\
(95 \% \mathrm{Cl})\end{array}$} & \multirow{2}{*}{$\begin{array}{l}\text { AOR } \\
(95 \% \mathrm{Cl})\end{array}$} & \multirow{2}{*}{$\begin{array}{l}P \text { - } \\
\text { value }\end{array}$} \\
\hline & & Use & $\begin{array}{l}\text { Do not } \\
\text { use }\end{array}$ & & & \\
\hline \multirow[t]{2}{*}{ Work Experience } & $>6$ years & $31(20.4)$ & $\begin{array}{l}121 \\
(79.6)\end{array}$ & 1 & 1 & \\
\hline & $\leq 6$ years & $76(30.4)$ & $\begin{array}{l}174 \\
(69.6)\end{array}$ & $\begin{array}{l}1.70 \\
(1.06- \\
2.75)\end{array}$ & $\begin{array}{l}2.13(1.08- \\
4.20)\end{array}$ & 0.03 \\
\hline \multirow[t]{2}{*}{ Computer skill } & Poor & $\begin{array}{l}40 \\
(20.0)\end{array}$ & $\begin{array}{l}160 \\
(80.0)\end{array}$ & 1 & 1 & \\
\hline & Fair & $\begin{array}{l}67 \\
(33.2)\end{array}$ & $\begin{array}{l}135 \\
(66.8)\end{array}$ & $\begin{array}{l}1.98 \\
(1.26- \\
3.12)\end{array}$ & $\begin{array}{l}1.32(0.68- \\
2.56)\end{array}$ & 0.41 \\
\hline \multirow[t]{2}{*}{ Smart care training } & No & $\begin{array}{l}26 \\
(19.3)\end{array}$ & $\begin{array}{l}109 \\
(80.7)\end{array}$ & 1 & 1 & \\
\hline & Yes & $\begin{array}{l}81 \\
(30.3)\end{array}$ & $\begin{array}{l}186 \\
(69.7)\end{array}$ & $\begin{array}{l}1.82 \\
(1.10- \\
3.01)\end{array}$ & $\begin{array}{l}0.45(0.20- \\
1.01)\end{array}$ & 0.06 \\
\hline \multirow[t]{2}{*}{ Presence of EMR manual } & No & $\begin{array}{l}66 \\
(19.5)\end{array}$ & $\begin{array}{l}273 \\
(80.5)\end{array}$ & 1 & 1 & \\
\hline & Yes & $\begin{array}{l}41 \\
(65.1)\end{array}$ & $\begin{array}{l}22 \\
(34.9)\end{array}$ & $\begin{array}{l}7.71(4.30- \\
13.82)\end{array}$ & $\begin{array}{l}3.01(1.23- \\
7.40)\end{array}$ & 0.02 \\
\hline \multirow[t]{2}{*}{$\begin{array}{l}\text { Discuss on EMR on any } \\
\text { meeting }\end{array}$} & No & $\begin{array}{l}62 \\
(17.9)\end{array}$ & $\begin{array}{l}284 \\
(821)\end{array}$ & 1 & 1 & \\
\hline & Yes & $\begin{array}{l}45 \\
(80.4)\end{array}$ & $\begin{array}{l}11 \\
(19.6)\end{array}$ & $\begin{array}{l}18.74 \\
(9.2-38.3)\end{array}$ & $\begin{array}{l}15.23(5.70- \\
40.74)\end{array}$ & 0.001 \\
\hline \multirow[t]{2}{*}{ Perceived service quality } & Poor & $23(9.9)$ & $\begin{array}{l}209 \\
(90.1)\end{array}$ & 1 & 1 & \\
\hline & Good & $\begin{array}{l}84 \\
(49.4)\end{array}$ & $\begin{array}{l}86 \\
(50.6)\end{array}$ & $\begin{array}{l}8.88(5.25- \\
15.00)\end{array}$ & $\begin{array}{l}8.31(4.11- \\
16.80)\end{array}$ & 0.001 \\
\hline \multirow[t]{2}{*}{$\begin{array}{l}\text { Perceived information } \\
\text { quality }\end{array}$} & Poor & $\begin{array}{l}25 \\
(14.4)\end{array}$ & $\begin{array}{l}149 \\
(85.6)\end{array}$ & 1 & 1 & \\
\hline & Good & $\begin{array}{l}82 \\
(36.0)\end{array}$ & $\begin{array}{l}146 \\
(64.0)\end{array}$ & $\begin{array}{l}3.35 \\
(2.02- \\
5.53)\end{array}$ & $\begin{array}{l}1.87(0.85- \\
4.08)\end{array}$ & 0.12 \\
\hline \multirow[t]{2}{*}{ Perceived system quality } & Poor & $13(6.8)$ & $\begin{array}{l}178 \\
(93.2)\end{array}$ & 1 & 1 & \\
\hline & Good & 94 & 117 & 11.00 (5.9- & 7.38 (2.97- & 0.001 \\
\hline
\end{tabular}




\begin{tabular}{|c|c|c|c|c|c|c|}
\hline & & (44.6) & (55.4) & 20.55) & 18.34) & \\
\hline \multirow[t]{2}{*}{$\begin{array}{l}\text { Perceived EMR benefit to } \\
\text { facility }\end{array}$} & $\begin{array}{l}\text { Do not } \\
\text { benefit }\end{array}$ & $67(23.4)$ & $\begin{array}{l}219 \\
(76.6)\end{array}$ & 1 & 1 & \\
\hline & Benefit & $\begin{array}{l}40 \\
(34.5)\end{array}$ & $\begin{array}{l}76 \\
(65.5)\end{array}$ & $\begin{array}{l}1.72 \\
(1.07- \\
2.75)\end{array}$ & $\begin{array}{l}0.33(0.06- \\
1.65\end{array}$ & 0.18 \\
\hline \multirow[t]{2}{*}{$\begin{array}{l}\text { Perceived EMR benefit to } \\
\text { the patients }\end{array}$} & $\begin{array}{l}\text { Do not } \\
\text { benefit }\end{array}$ & $\begin{array}{l}65 \\
(22.0)\end{array}$ & $\begin{array}{l}231 \\
(78.0)\end{array}$ & 1 & 1 & \\
\hline & Benefit & $\begin{array}{l}42 \\
(39.6)\end{array}$ & $\begin{array}{l}64 \\
(60.4)\end{array}$ & $\begin{array}{l}2.33 \\
(1.45- \\
3.76)\end{array}$ & $\begin{array}{l}5.51(1.10- \\
27.67)\end{array}$ & 0.04 \\
\hline
\end{tabular}

\section{Challenges of EMR use (Qualitative finding)}

Multiple factors that influence EMR use were cited by key informants during in-depth interview. Common themes were organized as Organizational, technical, and behavioral factors during analysis. The most common significant barrier cited by key informants for not using EMR was lack of EMR software installed on the computers as well as lack of management commitment to integrate EMR into patient data recording.

HMIS focal person from Dire Dawa City health bureau reported;

"Poor commitment from all health professionals and governing body working in the facilities takes the major share of barriers. Some health professionals are not even interested and motivated to manually record patient data. Some health professionals also consider working with computer as an extra burden". This finding is supplemented by the quantitative finding where despite training on EMR, most health professionals were not using it.

Another point raised by key informants is health professional's attitude towards EMR. Some respondents cited that some health professionals get agitated with filling data in computers and rather prefer to use paper based record.

Technical factors were also cited as one factor for not using EMR. A 32 years old HIT staff at one of the health facility said 'If the programme malfunctioned or corrupted, there was no timely maintenance. He added "There was no replacement for even a single malfunctioned Socket or divider."

\section{Discussion}

This study revealed that only a quarter of health professionals were using EMR. This finding is low compared to a finding in USA ${ }^{13}$, Hyder hospital in Tigray and Amhara states in Ethiopia. ${ }^{23,30,31}$ None of the urban health facilities had fully functional EMR system. Few service delivery units such as ART clinics and patient registration offices were using EMR system in conjunction with paper based records. This resulted from technical challenges related to the EMR, non-functional computers, electricity interruption, 
and lack of timely maintenance and repair of computers. Moreover, health care providers' behavioural factors including poor computer literacy, poor commitment, and lack of interest in adapting to electronic recording.

This study also found that poor collaboration from stakeholders and dependence on NGOs for EMR programme were cited as major factors. Respondents indicated that during in-depth interview that the software was designed by NGO (Tulane University) and after the project phased out, the EMR service also stopped due to Lack of appropriate infrastructure for integration of EMR with other existing information system. Other studies indicated that dependence of developing countries on third-party vendor systems for EMR which usually involve unsustainable IT infrastructure and software management have been identified as significant barriers in EMR implementations. ${ }^{24,32-34}$

However, this study finding goes in line with other study conducted in Ethiopia's Amhara Region ${ }^{31}$ and in Addis Ababa. ${ }^{23}$ Lack of administrative and policy support and Lack of available funding were cited by key informants as a major barrier to EMR use. More than two third of the respondents accepts EMR implementation and the positive effects of these systems on several dimensions of quality of care which is supported by study conducted in Tigray region ${ }^{26}$ and USA ${ }^{35}$ Literatures indicated that most health professionals have accepted the role of automated notes and records in improving health care quality 8,36 though lack of infrastructure hindered the full implementation of the system. In general barriers associated with hardware and software resource were the most commonly cited barriers to EMR use by health professionals in this study.

Health professionals with work experience of 6 years or less were by two folds more likely to use EMR compared to those with work experience greater than 6 years. This finding is similar to study finding conducted in northern Ethiopia. ${ }^{26}$ Studies showed that the gap in knowledge and skill of health workers significantly influences data management processes $(1,37)$. Variation in computer literacy, educational level and personal commitment in this study could be an explanation for low EMR use among health professionals. Having discussion on EMR and presence of EMR manual are predictor of EMR use in this study. These findings are in line with other studies elsewhere in Ethiopia $20,23,26$, and USA. ${ }^{38}$

In contrast to studies conducted in different regions of Ethiopia ${ }^{23,26,37}, \operatorname{Iran}^{39}, \mathrm{USA}^{38}$, and Cyprus ${ }^{40}$ training on EMR system had no influence on EMR use in our study. From logical point of view, it is true that training can change the knowledge, attitude and skills of health professionals. However, having adequate training cannot be a driving factor unless EMR system is continuously maintained and staffs are motivated to use EMR. In addition, key informants stated that trainings have not reached to those who actively engaged in EMR including card room and ART units. Inadequate IT professionals have also been cited by key informants as reasons for low utilization.

Further, this study revealed that attitude towards EMR system quality influences utilization of the EMR system. Health professionals with good attitude on EMR service quality and EMR system quality more likely to use EMR than their counterparts respectively. This finding is similar to study conducted in in 
Addis Ababa. ${ }^{23}$ This is evident as users' acceptance is the primary determinant of effective utilization of any program. ${ }^{41,42}$

The qualitative finding identified major organizational, technical and behavioral factors as the major obstacles to EMR use by health professionals. These determinants have also been cited by other studies from USA ${ }^{43}$, Saudi Arabia ${ }^{28}$, and UK. ${ }^{29}$ Organizational $13,35,39,44$, technical, and most importantly behavioral ${ }^{38,39}$ factors were identified to be an important determinants hindering effective and efficient utilization of EMR.

This cross-sectional study included only urban public health facilities. An extensive overview of overall EMR utilization status requires inclusion of health posts, rural and private health facilities. The generalizability of the finding of this study may not apply to these facilities. Further, use was not assessed from a multilevel perspective across the individual and organizational levels.

\section{Conclusions}

The immense benefits of electronic medical records were very poorly utilized in this study area. Only a quarter of respondents used EMR in their day-to-day activities. Organizational determinants (EMR manual presence, absence of EMR software program, smart care training, and attending regular discussion on EMR) and individual factors (attitudes on benefit of EMR to patients, perceived system quality and service quality) had significant influence on the utilization of EMR. Successful utilization of EMR requires support and commitment of all stakeholders. Interventions should focus to improve user support, power fluctuation, computer infrastructure, and continuous trainings.

\section{Abbreviations}

AOR: Adjusted Odds ratio

ART: Antiretroviral Treatment

CDC: Communicable Disease Control

Cl: Confidence Interval

EMR: Electronic Medical Record

HIT: Health Informatics technicians

HMIS: Health Management Information System

HSTP: Health Sector Transformation Plan

IHRERC: Institutional Health Research Ethic Review Committee 
IT: Information Technology

NGO: Non-Governmental Organizations

SD: Standard Deviation

TUTAPE: Tulane University Technical Assistance Project in Ethiopia

UK: United Kingdom

USA: United states of America

\section{Declarations}

\section{Ethics approval and consent to participate}

The study was conducted in accordance to the declaration of Helsinki. The study protocol was approved by Institutional Health Research Ethics Review Committee (IHRERC) of Haramaya University, College of Health and Medical Sciences (Ref. No: IHRERC/104/2019). Thus, informed, written and signed consent was obtained from each participant. In order to protect the confidentiality of the information, names and identity number of participants were not included in the questionnaires.

\section{Consent for publication}

Not applicable.

\section{Availability of data and materials}

All data generated or analysed during this study are included in this published article. The full datasets used and/or analyzed during the current study is available from the corresponding author on reasonable request.

\section{Conflict of interest}

The authors declare that they have no competing interests.

\section{Funding Source}

This work was funded by Haramaya University.

\section{Authors' contribution}

AT initiated the study. LO, TD, AAA and HS assisted in the design, collection, analysis and interpretation and thoroughly revised the manuscript. AT prepared the first draft manuscript and LO, TD, AA and HS thoroughly revised the draft and substantially contributed in the finalization of the manuscript. All authors read and approved the final manuscript. 
Acknowledgements

The authors are grateful to data collectors and participating facilities in Dire Dawa for their assistance during data collection. Lastly we would like to acknowledge Haramaya University for funding this study.

\section{References}

1. EFMoH. (Ethiopian Federal ministry of Health); 'Information Revolution Roadmap' Addis Ababa, Ethiopia. 2016.

2. Chiuchisan I, Costin H, Geman O, editors. Adopting the Internet of Things technologies in health care systems. 2014 International Conference and Exposition on Electrical and Power Engineering (EPE); 2014 16-18 Oct. 2014.

3. Beyette FR, Gaydos CA, Kost GJ, Weigl BH. Point-of-Care Technologies for Health Care. IEEE Transactions on Biomedical Engineering. 2011;58(3):732-5.

4. Hillestad R, Bigelow J, Bower A, Girosi F, Meili R, Scoville R, et al. Can Electronic Medical Record Systems Transform Health Care? Potential Health Benefits, Savings, And Costs. Health Affairs. 2005;24(5):1103-17.

5. Chaudhry B, Wang J, Wu S, Maglione M, Mojica W, Roth E, et al. Systematic review: impact of health information technology on quality, efficiency, and costs of medical care. 2006;144(10):742-52.

6. Krist AH, Green LA, Phillips RL, Beasley JW, DeVoe JE, Klinkman MS, et al. Health Information Technology Needs Help from Primary Care Researchers. 2015;28(3):306-10.

7. Tomasi E, Facchini LA, Maia MF. Health information technology in primary health care in developing countries: a literature review. Bulletin of the World Health Organization. 2004;82(11):867-74.

8. Amarasingham R, Plantinga L, Diener-West M, Gaskin DJ, Powe NRJAoim. Clinical information technologies and inpatient outcomes: a multiple hospital study. 2009;169(2):108-14.

9. Lin SC, Jha AK, Adler-Milstein J. Electronic health records associated with lower hospital mortality after systems have time to mature. 2018;37(7):1128-35.

10. Häyrinen K, Saranto K, Nykänen P. Definition, structure, content, use and impacts of electronic health records: a review of the research literature. 2008;77(5):291-304.

11. Garets D, Davis M. Electronic medical records vs. electronic health records: yes, there is a difference. Policy white paper. Chicago, HIMSS Analytics. 2006:1-14.

12. O'Donnell A, Kaner E, Shaw C, Haighton C. Primary care physicians' attitudes to the adoption of electronic medical records: a systematic review and evidence synthesis using the clinical adoption framework. BMC Medical Informatics and Decision Making. 2018;18(1):101.

13. Gabriel MH, Jones EB, Samy L, King JJHA. Progress and challenges: implementation and use of health information technology among critical-access hospitals. 2014;33(7):1262-70.

14. Meinert DB. Resistance to Electronic Medical Records(EMRs): A Barrier to Improved Quality of Care. 2005;2:493-504. 
15. Russo E, Sittig DF, Murphy DR, Singh H. Challenges in patient safety improvement research in the era of electronic health records. Healthcare. 2016;4(4):285-90.

16. Saleem JJ, Russ AL, Justice CF, Hagg H, Ebright PR, Woodbridge PA, et al. Exploring the persistence of paper with the electronic health record. International Journal of Medical Informatics. 2009;78(9):618-28.

17. Abiy R, Gashu K, Asemaw T, Mitiku M, Fekadie B, Abebaw Z, et al. A comparison of electronic records to paper records in Antiretroviral Therapy Clinic in Ethiopia: What is affecting the Quality of the Data? 2018. 2018;10(2).

18. Sikhondze NC, Erasmus L. Electronic medical records: a developing and developed country analysis. 2016.

19. Adler-Milstein J, DesRoches CM, Kralovec P, Foster G, Worzala C, Charles D, et al. Electronic health record adoption in US hospitals: progress continues, but challenges persist. 2015;34(12):2174-80.

20. Biruk S, Melesse T, Andualem M, Tilahun B. Health Professionals Readiness to Implement Electronic Medical Record System at Three Hospitals in Ethiopia: a cross sectional study2014. 115 p.

21. Jawhari B, Ludwick D, Keenan L, Zakus D, Hayward R. Benefits and challenges of EMR implementations in low resource settings: a state-of-the-art review. BMC Medical Informatics and Decision Making. 2016;16(1):116.

22. Kemkarl O, Dahikar D. Can electronic medical record systems transform health care? potential health benefits, savings, and cost using latest advancements in ict for better interactive healthcare learning. 2012;2(3/6):453-5.

23. Tilahun B, Fritz F. Comprehensive evaluation of electronic medical record system use and user satisfaction at five low-resource setting hospitals in ethiopia. JMIR medical informatics. 2015;3(2):e22-e.

24. Mengesha T. Electronic solutions for Ethiopian health sector. Autumn: Oulu University. 2011.

25. USAID. (United States Agency for International Development) Performance of Routine Information System Management (PRISM) Toolkit, ISBN: 978-1-64232-065-7; https://www.measureevaluation.org/resources/tools/rhis-rat/routine-health-information-systemrapid-assessment-tool), 2019.

26. Yehualashet G, Asemahagn, M. and Tilahun, B. "The Attitude towards and Use of Electronic Medical Record System by Health Professionals at a Referral Hospital in Northern Ethiopia: Cross-Sectional Study", Journal of Health Informatics in Africa, 3(1). 2015.

27. Teklegiorgis K, Tadesse K, Terefe W, Mirutse G. Level of data quality from Health Management Information Systems in a resources limited setting and its associated factors, eastern Ethiopia: original research. 2016;18(1):1-8.

28. Khalifa M. Barriers to Health Information Systems and Electronic Medical Records Implementation. A Field Study of Saudi Arabian Hospitals. Procedia Computer Science. 2013;21:335-42.

29. Murray E, Burns J, May C, Finch T, O'Donnell C, Wallace P, et al. Why is it difficult to implement ehealth initiatives? A qualitative study. 2011;6(1):6. 
30. Berhe M, Tadesse K, Berhe G, Gebretsadik T. Evaluation of Electronic Medical Record Implementation from User's Perspectives in Ayder Referral Hospital Ethiopia. 2017;8(249):2.

31. Andualem Asemahagn $M$. The functionality status and challenges of electronic health management information system: The case of public health centres in Amhara Region, Ethiopia. Cogent Medicine. 2018;5(1).

32. Wong R, Bradley EH. Developing patient registration and medical records management system in Ethiopia. International Journal for Quality in Health Care. 2009;21(4):253-8.

33. Heeks RJTis. Information systems and developing countries: Failure, success, and local improvisations. 2002;18(2):101 - 12.

34. Rotich JK, Hannan TJ, Smith FE, Bii J, Odero WW, Vu N, et al. Installing and implementing a computer-based patient record system in sub-Saharan Africa: the Mosoriot Medical Record System. Journal of the American Medical Informatics Association: JAMIA. 2003;10(4):295-303.

35. DesRoches CM, Campbell EG, Rao SR, Donelan K, Ferris TG, Jha A, et al. Electronic health records in ambulatory care-a national survey of physicians. 2008;359(1):50-60.

36. Sukums F, Mensah N, Mpembeni R, Kaltschmidt J, Haefeli WE, Blank A. Health workers' knowledge of and attitudes towards computer applications in rural African health facilities. Global health action. 2014;7(1):24534.

37. Gebre-Mariam M, Borycki E, Kushniruk A, Purkis ME. An Electronic Medical Record (EMR) Implementation Framework for HIV Care and Treatment Facilities in Ethiopia2012.

38. Holden RJ. What stands in the way of technology-mediated patient safety improvements? A study of facilitators and barriers to physicians' use of electronic health records. Journal of patient safety. 2011;7(4):193.

39. Ayatollahi H, Mirani N, Haghani H. Electronic health records: what are the most important barriers? Perspectives in health information management. 2014;11(Fall):1c-c.

40. Samoutis G, Soteriades ES, Kounalakis DK, Zachariadou T, Philalithis A, Lionis C. Implementation of an electronic medical record system in previously computer-naive primary care centres: a pilot study from Cyprus. 2007;15(4).

41. Rao SR, DesRoches CM, Donelan K, Campbell EG, Miralles PD, Jha AK. Electronic health records in small physician practices: availability, use, and perceived benefits. Journal of the American Medical Informatics Association. 2011;18(3):271-5.

42. Raja EEJ, Mahal R, Masih VB. An exploratory study to assess the computer knowledge, attitude and skill among nurses in health care setting of a selected hospital in Ludhiana, Punjab, India. Stud Health Technol Inform. 2004;107(Pt 2):1304-7.

43. Yoon-Flannery K, Zandieh S, Kuperman G, Langsam D, Hyman D, Kaushal R. A qualitative analysis of an electronic health record (EHR) implementation in an academic ambulatory setting. $2008: 8 \% \mathrm{~J}$ Journal of Innovation in Health Informatics.

44. Gyamfi A, Mensah KA, Oduro G, Donkor P, Mock CN. Barriers and facilitators to Electronic Medical Records usage in the Emergency Centre at Komfo Anokye Teaching Hospital, Kumasi-Ghana. African 
Journal of Emergency Medicine. 2017;7(4):177-82.

\section{Figures}

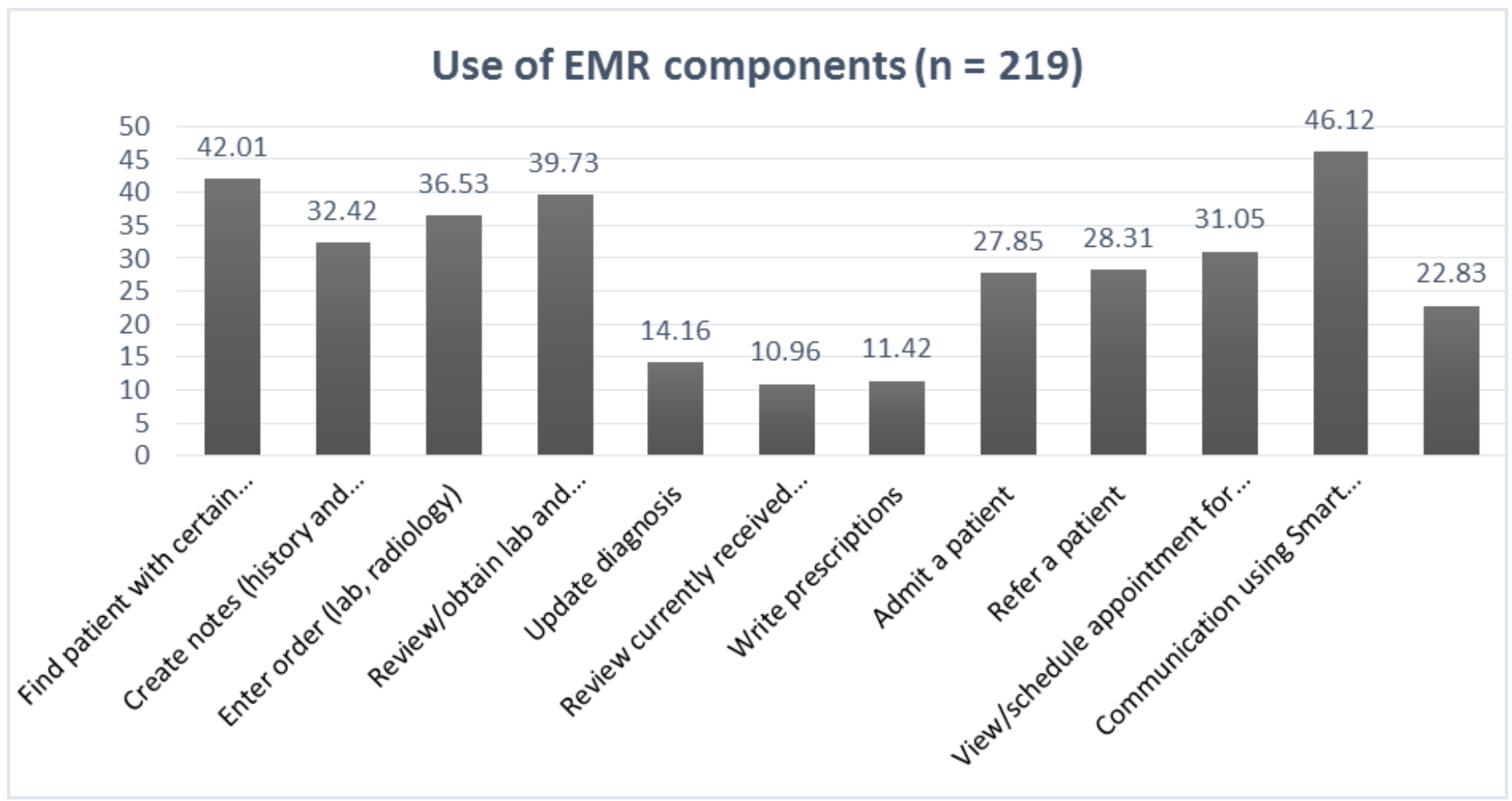

Figure 1

Use of the basic EMR components by health professionals, Dire Dawa, Ethiopia, 2019. 
Reasons for not using EMR currently ( $n=295$ )

120

100

96.27

80

65.76

69.15

60
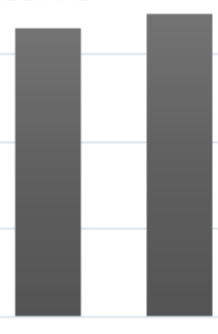

$2.37 \quad 2.03$

0 45.08

40

20
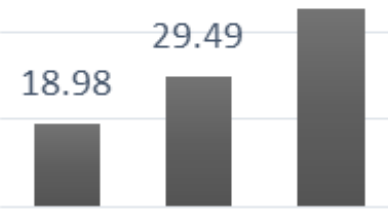

20

17.97
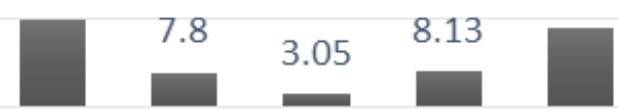

ㄴ

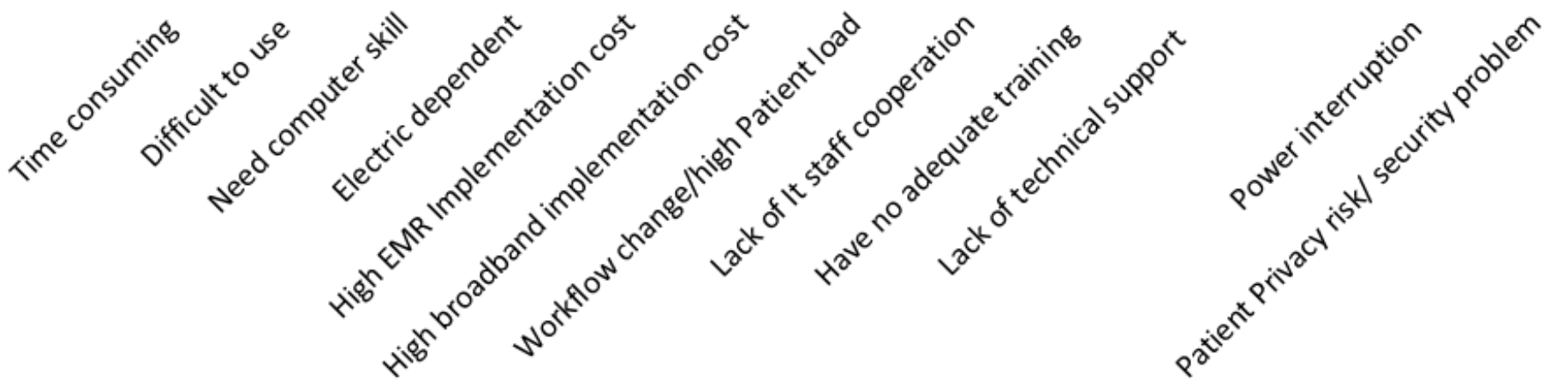

Figure 2

Reported reasons for not currently using the EMR system Dire Dawa, Ethiopia, 2019.

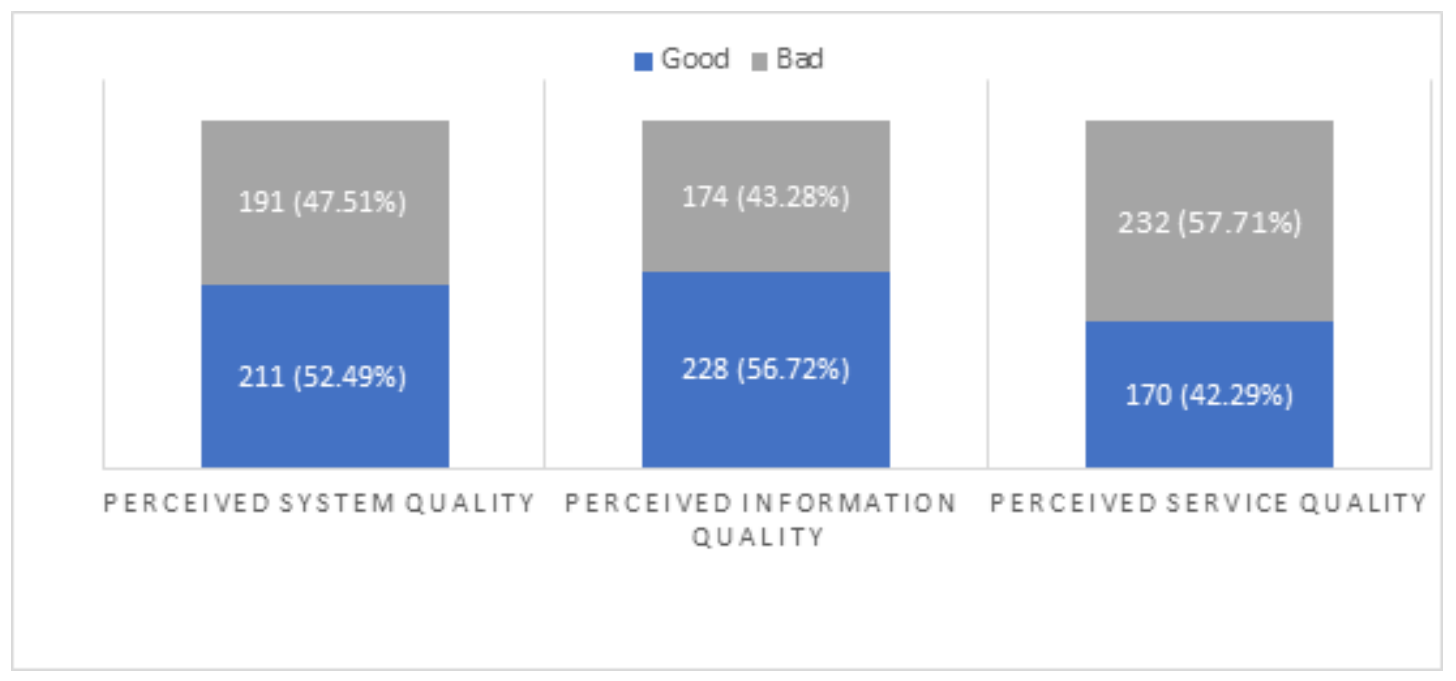

Figure 3 
Study participants' perceived EMR system, information, and EMR service quality, Dire Dawa, Ethiopia, 2019. 